\title{
Normal uterine size in women of reproductive age in northern Islamic Republic of Iran
}

\author{
S. Esmaelzadeh, ${ }^{1}$ N. Rezaei ${ }^{1}$ and M. HajiAhmadi ${ }^{2}$
}

\begin{abstract}
SUMMARY To determine the efficacy of ultrasonographic assessment of uterus size in women of reproductive age, we conducted a cross-sectional analytic study of 231 women aged 15-45 years in Babol, northern Islamic Republic of Iran. Mean uterus size was $86.6 \mathrm{~mm} \times 49.6 \mathrm{~mm} \times 40.6 \mathrm{~mm}$ overall, $72.8 \mathrm{~mm} \times 42.8 \mathrm{~mm}$ $\times 32.4 \mathrm{~mm}$ for nulliparous women and $90.8 \mathrm{~mm} \times 51.7 \mathrm{~mm} \times 43.0 \mathrm{~mm}$ for multiparous women. Mean age was $31.7 \pm 9.6$ years and mean body mass index (BMI) was $24.7 \pm 4.0 \mathrm{~kg} / \mathrm{m}^{2}$. Uterus size was significantly associated with parity and age, but not with BMI. Our findings show a greater mean uterus size than reported by others. Ultrasonographic measurement of uterus size is valuable for predicting pathologies associated with abnormal uterine size.
\end{abstract}

\section{Introduction}

Knowledge of the normal dimensions of the uterus is important for evaluating the health status of women and for forecasting the risk of developing some of the many diseases seen by gynaecologists and obstetricians. Ultrasonography is particularly suited to the diagnostic investigation of uterine size because it limits the patient's exposure to ionizing radiation, permits multi-sectional scanning of organs and is convenient and relatively inexpensive to use [1].

It is currently possible to predict the development of diseases such as uterine myoma and adenomyosis if the specific sonographic measurements are known [2]. Vaginal and abdominal sonography are effective for determining the dimensions of the uterus, allowing the organ to be exam- ined to a potential depth of $10 \mathrm{~cm}$ (if the patient retains a full bladder). It is necessary to use a transmitter with a long focal centre, for which real-time scanning is the method of choice [3].

The 3 dimensions of the uterus must be assessed. Length is measured from the fundus to the external os. The anteroposterior diameter is the maximum length in the midsagittal section of the body of the uterus in the anteroposterior direction. For evaluation of the length and anteroposterior diameter, the probe is located on the suprapubic area in a longitudinal direction. For estimation of uterine width, it is suggested that the transducer be rotated up to 90 degrees to facilitate assessment of the transverse diameter. Uterine width is the maximum measurement obtained in a cross-section of the fundus $[4,5]$.

${ }^{1}$ Department of Obstetrics and Gynaecology, Shaheed Yahyanejad Teaching Hospital; ${ }^{2}$ Department of Statistics, Babol University of Medical Sciences, Babol, Mazandaran Province, Islamic Republic of Iran.

Received: 16/05/02; accepted: 06/08/02

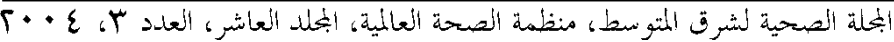


The form and size of the uterus change with an individual's age and obstetric history. During fetal life, the size of the uterus initially increases at a slow rate until the end of the first trimester, after which it increases in size at a faster rate due to the increased production of maternal estrogen. Immediately after delivery the size of the uterus decreases, a result of the cessation of maternal estrogen.

Between the ages of 2 and 8 years, uterine length is less than $35 \mathrm{~mm}$, with an anteroposterior diameter of $10 \mathrm{~mm}[4,7]$. During puberty, the ovaries begin to secrete hormones. At this time, the uterus is a pearshaped organ. During a woman's lifetime, the changes in morphology of the uterus result from changes to the muscular layer, particularly in the body portion [6]. The fundus of the uterus becomes thicker with each pregnancy. After menopause, the fundus reverts to its pubertal form in such a way that it can be palpated over the cervix, at which time its size is similar to that of a cup. A length of $10 \mathrm{~cm}$ is considered to be normal for a woman of reproductive age [8].

It is known that growth criteria (height, weight, other body indices) are influenced by race, heredity, environment and nutrition $[9,10]$. We therefore sought to investigate the normal dimensions of the uterus in Iranian women, mindful that any abnormality in uterine dimensions may be suggestive of a pathologic condition.

\section{Methods}

Following approval by the research committee of Babol University of Medical Sciences teaching hospital, an analytical descriptive cross-sectional study was conducted on a cohort of 231 healthy women of reproductive age (15-45 years). Women with abnormal uterine anatomy, uterine bleeding or pathology of the pelvis were excluded from the study. The study had the approval of the local ethics committee and informed consent was obtained from all participants.

In measuring the uterus by sonography, factors such as pressure exerted by adjacent organs and the woman's menstrual period were considered. Height, weight, parity and age were also recorded. The women were divided into 2 groups based on parity: nulliparous (never having borne children) and multiparous (having borne $\geq 1$ child). They were further classified according to body mass index (BMI) into acceptable (BMI 20-24.99 kg/m²), overweight (BMI 25-29.99 $\mathrm{kg} / \mathrm{m}^{2}$ ) and obese $\left(\mathrm{BMI} \geq 30 \mathrm{~kg} / \mathrm{m}^{2}\right)$.

Sonography was carried out by a sonographist using abdominal sonography equipment (Shimadzu convex probe, 3.5 $\mathrm{MHz}$ ). Data were analysed using SPSS software and interpreted using Student $t$ test, Pearson correlation coefficient and analysis of variance.

\section{Results}

Of the 231 women in the study, 54 (23.4\%) were nulliparous and 177 (76.6\%) multiparous (mean parity: $2.7 \pm 2.4$ children). Mean uterine size overall was $86.6 \mathrm{~mm} \times$ $49.6 \mathrm{~mm} \times 40.6 \mathrm{~mm}$ (length $\times$ width $\times$ anteroposterior diameter). Uterine size was significantly correlated with parity $(P$ $<0.001$ ) (Table 1).

Mean age was $31.7 \pm 9.6$ years. Uterine size was also significantly correlated with age $(P<0.001)$. Mean weight was $65.5 \pm$ $10.5 \mathrm{~kg}$, mean height $162.9 \pm 5.9 \mathrm{~cm}$ and mean BMI $24.7 \pm 4.0 \mathrm{~kg} / \mathrm{m}^{2}$, with $48.8 \%$ of the women in the study with BMI 20-24.99 $\mathrm{kg} / \mathrm{m}^{2}, 39.9 \%$ with BMI $25-29.99 \mathrm{~kg} / \mathrm{m}^{2}$ and $11.3 \%$ with $\mathrm{BMI} \geq 30 \mathrm{~kg} / \mathrm{m}^{2}$ (Table 2 ). It is clear from the data on Table 2 that

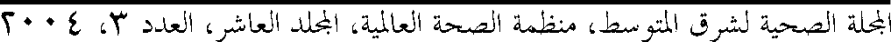




\begin{tabular}{|c|c|c|c|c|}
\hline \multirow[t]{2}{*}{ Parity } & \multirow{2}{*}{$\begin{array}{l}\text { Age (years) } \\
\text { mean } \pm \text { SEM }\end{array}$} & \multicolumn{3}{|c|}{ Uterine dimensions ( $\mathrm{mm}$ ) } \\
\hline & & $\begin{array}{c}\text { Length, } \\
\text { mean } \pm \text { SEM }\end{array}$ & $\begin{array}{c}\text { Anteroposterior } \\
\text { diameter, } \\
\text { mean } \pm \text { SEM }\end{array}$ & $\begin{array}{c}\text { Width, } \\
\text { mean } \pm \text { SEM }\end{array}$ \\
\hline $\begin{array}{l}\text { Nulliparous } \\
\qquad(n=54)\end{array}$ & $21.5 \pm 0.7$ & $72.8 \pm 1.3$ & $32.4 \pm 0.1$ & $42.8 \pm 1.2$ \\
\hline $\begin{array}{l}\text { Multiparous } \\
\qquad(n=117)\end{array}$ & $34.3 \pm 0.6$ & $90.8 \pm 1.1$ & $43.0 \pm 0.8$ & $51.7 \pm 0.7$ \\
\hline$P$-value & $<0.001$ & $<0.001$ & $<0.001$ & $<0.001$ \\
\hline
\end{tabular}

SEM = standard error of the mean.

there is no statistically significant correlation between BMI and uterus size.

\section{Discussion}

The results of our study differ from those obtained by a number of previous researchers elsewhere. Our finding of an overall mean uterus size of $86.6 \mathrm{~mm} \times 49.6 \mathrm{~mm} \times$ $40.6 \mathrm{~mm}$ (length $\times$ width $\times$ anteroposterior diameter) contrasts with that of Warwick and Banister (mean uterus size $75.0 \mathrm{~mm} \times$ $25.0 \mathrm{~mm} \times 50.0 \mathrm{~mm}$ ) [11]. Our finding of mean uterus size for nulliparous and multiparous women of $72.8 \mathrm{~mm} \times 42.0 \mathrm{~mm} \times$
$32.4 \mathrm{~mm}$ and $90.8 \mathrm{~mm} \times 51.7 \mathrm{~mm} \times 43.0$ $\mathrm{mm}$ respectively also contrasts with the 1994 results of Holt et al. $(70.0 \mathrm{~mm} \times 40.0$ $\mathrm{mm} \times 40.0 \mathrm{~mm}$ for nulliparous women) [2], the 1997 results of Waldroup and Liu $(80.0 \mathrm{~mm} \times 30.0 \mathrm{~mm} \times 55.0 \mathrm{~mm}$, all women) [4], and the 1991 results of Sanders $(60.0-90.0 \mathrm{~mm} \times 40.0 \mathrm{~mm} \times 40.0 \mathrm{~mm}$ for nulliparous women) [7]. Our findings were similar to the 1997 investigations of Cunningham in which the length of the uterus was reported to be $60.0-80.0 \mathrm{~mm}$ in nulliparous women and $90.0-100.0 \mathrm{~mm}$ in multiparous women [12].

\begin{tabular}{|c|c|c|c|}
\hline \multirow[t]{2}{*}{$B M I\left(k g / m^{2}\right)$} & \multicolumn{3}{|c|}{ Uterine dimensions ( $\mathrm{mm}$ ) } \\
\hline & $\begin{array}{c}\text { Length, } \\
\text { mean } \pm \text { SEM }\end{array}$ & $\begin{array}{c}\text { Anteroposterior } \\
\text { diameter, } \\
\text { mean } \pm \text { SEM }\end{array}$ & $\begin{array}{c}\text { Width, } \\
\text { mean } \pm \text { SEM }\end{array}$ \\
\hline $20-24.99(n=113)$ & $86.5 \pm 1.5$ & $40.3 \pm 0.9$ & $49.9 \pm 0.9$ \\
\hline $25-29.99(n=92)$ & $87.3 \pm 1.9$ & $39.9 \pm 1.1$ & $49.2 \pm 1.2$ \\
\hline$\geq 30(n=26)$ & $88.8 \pm 2.6$ & $44.5 \pm 2.0$ & $49.3 \pm 2.6$ \\
\hline$P$-value & 0.787 & 0.148 & 0.882 \\
\hline
\end{tabular}

SEM = standard error of the mean.

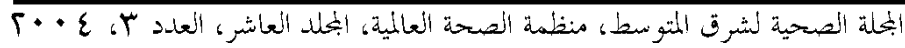


The difference in uterus measurements obtained in our study from those reported in other countries may be due to the impact of factors such as race, heredity, environment and diet. Our finding of a marked difference in the mean uterine size of multiparous and nulliparous women owing to the effects of delivery on the uterus is in accordance with the findings of Waldroup and Liu and Cunningham $[4,12]$.

The direct correlation between age and uterus size seen in our study (which is in agreement with the findings of Waldroup and Liu) may be due to changes over a woman's lifespan in ovarian estrogen secretion. Uterine growth continues during the reproductive years of a woman's life and ceases at menopause, ultimately regressing in size to approximate its pubertal form [4]. This pattern was borne out in the present study.
The mean BMI of $24.7 \pm 4.0 \mathrm{~kg} / \mathrm{m}^{2}$ seen in the study was not significantly correlated with uterus size. Of the 231 women in the study, 48.8\% had acceptable BMI values, $39.9 \%$ were overweight and $11.3 \%$ were obese. These results contrast with the findings of Spiroffe and Galass [9], where mean BMI was $26.3 \mathrm{~kg} / \mathrm{m}^{2}$, however, as in our study, $10-12 \%$ of their subjects had a BMI $\geq 30 \mathrm{~kg} / \mathrm{m}^{2}$. In the present study, the mean uterus size for women with an acceptable BMI was $86.5 \mathrm{~mm} \times 49.9 \mathrm{~mm} \times$ $40.3 \mathrm{~mm}$ (length $\times$ width $\times$ anteroposterior diameter), for women in the overweight group, $87.3 \mathrm{~mm} \times 49.2 \mathrm{~mm} \times 39.9 \mathrm{~mm}$ and for women in the obese category, $88.8 \mathrm{~mm} \times 49.3 \mathrm{~mm} \times 44.5 \mathrm{~mm}$. In a review of the literature, we were unable to locate any studies in which the relationship between BMI and uterus size had been investigated.

\section{References}

1. Timor-Tritsch IE, Monteagudo A, Brown GM. Endovaginal sonographic valuation of the obstetrics and gynecology patient. In: Callen PW, ed. Ultrasonography in obstetrics and gynecology, 3rd ed. Philadelphia, WB Saunders, 1994:5.

2. Holt SC et al. Normal anatomy of the female pelvis. In: Callen PW, ed. Ultrasonography in obstetrics and gynecology, 3rd ed. Philadelphia, WB Saunders, 1994: 548-68.

3. Berman MC, Kawai D. Principles of scanning technique in obstetric and gynecologic ultrasound. In: Berman MC, Cohen $\mathrm{HL}$, eds. Diagnostic medical sonography: obstetrics and gynecology. Philadelphia, Lippincott, 1997:3-20.

4. Waldroup L, Liu JB. Sonographic anatomy of the female pelvis. In: Berman MC, Cohen HL, eds. Diagnostic medical sonography: obstetrics and gynecology. Philadelphia, Lippincott, 1997:51-9.

5. Timor-Tritsch IE, Moteagudo A. Scanning techniques in obstetrics and gynecology. Clinical obstetrics and gynecology, 1996, 39:167-74.

6. Kurtz AB, Rifkin MD. Normal anatomy of the female pelvis. In: Sanders RC, James $\mathrm{AE} \mathrm{Jr}$, eds. The principles and practice of ultrasonography in obstetrics and gynecology, 3rd ed. Norwalk Connecticut, Appleton Century Crofts, 1985:34.

7. Sanders RC. Clinical sonography: a practical guide, 2nd ed. Boston, LittleBrown, 1991:45-6.

8. Grunfeld L. The uterus and endometrium. Clinical obstetrics and gynecology, 1996, 39:175-87. 
9. Spiroff L, Galass RH. Clinical gynecologic endocrinology and infertility, 6th ed. Philadelphia, Lippincott, 1999:386 \& 781.

10. Sadler T.W. Longman's medical embryology, 8th ed. Philadelphia, Lippincott, Williams \& Wilkins, 2000:107.
11. Warwick W, Banister D. Gray's anatomy, 37th ed. London, Churchill Livingstone, 1989:1440-2.

12. Cunningham FG. Anatomy of the reproductive tract. In: Cunningham FG et al. eds. Williams obstetrics, 21st ed. London, Appleton \& Lange, 2001:43-7.

\section{Correction}

Knowledge of AIDS and self-efficacy to high-risk sexual practices among Lebanese males in New York. K.Z. Awad. Eastern Mediterranean Health Journal, 2002, Vol. 8 No. 6, pages $732-48$.

The author's name in Arabic should read: خصرّر عو ال

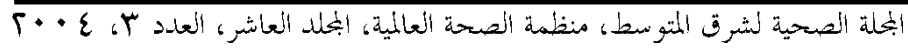

